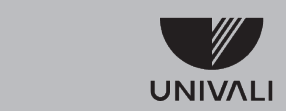

UNIVERSIDADE DO VALE DO ITAJAÍ

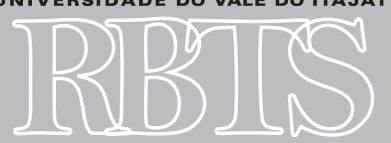

Revista Brasileira de Tecnologias Sociais
${ }^{1}$ Enfermeira. Mestranda em Saúde e Gestão do Trabalho - UNIVALI. Contato: marinahartcoph@ hotmail.com

${ }^{2}$ Docente. Universidade do Vale do Itajaí, Itajaí, SC - Brasil. Contato:ros@univali.br

${ }^{3}$ Docente. Universidade do Vale do Itajaí, Itajaí, SC - Brasil. Contato: agueda@univali.br

Autor correspondente: Marina Hartcoph. E-mail: marinahartcoph@hotmail.com

\section{Processo decisório e conselhos municipais de saúde: um estudo da realidade atual}

\section{The decision-making process and municipal health councils: a literature review}

Marina Hartcoph; Marco Aurélio da Ros; Agueda lenita Pereira Wendhausen

RESUMO: A participação social no Sistema Único de Saúde foi uma das principais conquistas do movimento pela Reforma Sanitária, que institucionalizou a participação da comunidade por meio de conferências e conselhos de saúde. Os últimos se constituem em importantes fóruns de decisões relativos ao planejamento e à efetivação de políticas de saúde, seja em âmbito federal, estadual, municipal ou local. Porém, esses espaços não têm sido tão democráticos quanto pensados na sua implantação. Considerando isso, este estudo tem por objetivo rever a literatura acerca do processo decisório nos conselhos de saúde, buscando conhecer os elementos que o compõem, como é concebido pelos membros e quais os fatores que interferem em sua execução. Espera-se contribuir para a qualificação do processo decisório nos conselhos de saúde, fortalecendo dessa maneira o controle social.

\section{Palavras-chave: Conselhos de saúde. Participação social. Controle social.}

ABSTRACT: Social participation in the National Health System was one of the main achievements of the Health Reform movement, which institutionalized community participation through conferences and health councils. The latter are important decision-making forums when it comes to planning and implementing health policies, whether at federal, state, municipal, or local levels. However, these spaces have not been as democratic as was initially hoped in their implementation. This study conducts a literature review of the decision-making process in the health councils, and the elements of this process, in the views of their members, and the factors that influence its execution. It is hope that this work will contribute to improving the decision-making process in the health councils, and thereby strengthen social control.

Keywords: Health councils. Social participation. Social control. 


\section{INTRODUÇÃO}

A participação social foi uma das principais conquistas do movimento pela Reforma Sanitária, indo sua compreensão além da expansão do direito e da reforma setorial, tinha como estratégia de democratização social "a saúde vista como potente conteúdo transformador" (LOBATO, 2009, p. 9).

Essa participação integrou a construção do Sistema Único de Saúde (SUS), criado pela Lei no 8.080/90 (BRASIL, 1990a). Tendo sido vetada nessa primeira legislação, foi no mesmo ano regulamentada pela Lei 8.142/90 (BRASIL, 1990b), que dispõe sobre a participação da comunidade na gestão do SUS.

A lei confere aos conselhos de saúde as atribuições de atuar na formulação de estratégias e no controle da execução das políticas de saúde - atribuições estas que são também próprias dos poderes executivo e legislativo. Entretanto, a atuação dos conselhos no controle da execução não deve ser meramente de fiscalização tradicional burocrática, mas sim de acompanhamento permanente da efetivação dos programas prioritários do SUS, de pesquisas por amostragem de usuários, prestadores e profissionais e de indicadores de saúde (BRASIL, 2002).

Os conselhos de saúde se constituem em importantes fóruns de decisões relativos ao planejamento e à execução de políticas de saúde nos âmbitos federal, estadual, municipal e local. Porém, sabe-se, através de pesquisas, que esses espaços não têm sido tão democráticos quanto pensados na sua implantação. Problemas na participação de conselheiros, tais como a dinâmica das reuniões se revelando apenas como momentos de aprovação e legitimação das decisões governamentais e não de explicitação de conflitos e negociação de ideias, perfil dos atores envolvidos, interlocução entre as entidades representadas, uso de linguagem inacessível a todos os representantes, têm sido apontados por diversos autores (WENDHAUSEN, 2002; BORBA, 2004; LABRA, 2002; KLEBA, 2005) como fatores limitantes a uma real participação democrática.

Normalmente é o governo que intervém nas políticas de saúde e não há sequer debate sobre temas importantes para que os serviços oferecidos se tornem mais consoantes com as necessidades da população. Deste modo, os conselhos de saúde têm sido muito mais um espaço para legitimar o que o segmento governamental deseja do que canal para demandas de todos, como pensado a priori, mesmo possuindo, em sua composição, representantes governamentais, de profissionais de saúde, de usuários e dos serviços privados de saúde (KLEBA; WENDHAUSEN, 2009).

O que acontece também é que o conselho mantém o status quo de uma saúde medicalizada, acaba atendendo às demandas mais organizadas e mais fortes, que são do setor privado da área da saúde. Os conselheiros, especialmente os da representação usuária e dos profissionais de saúde, não trazem à pauta os temas que lhe são concernentes e não conseguem discutir o que de fato mudaria os rumos da área da saúde, tornando-a coisa pública e mais integral, como pensada nos anos 1980, e consolidada no ideário implantado pelo SUS (KLEBA; WENDHAUSEN, 2009).

Portanto, torna-se importante saber mais sobre os conselhos de saúde para que se possam divulgar informações que influenciem de alguma maneira na atuação e na participação dos conselheiros, contribuindo assim para que espaços políticos se tornem mais democráticos.

Pretendeu-se, através de uma revisão da literatura, situar o processo decisório em termos de democracia participativa, descrever os elementos que o compõem, como é concebido pelos membros e quais os fatores que interferem para sua execução. Espera-se, com este estudo, contribuir para 
outras pesquisas e de alguma forma intervir formativamente junto aos sujeitos, de modo que possam participar, e por fim ajudar a levantar pontos que poderão auxiliar os conselheiros nesse processo.

\section{A INSTITUIÇÃO DOS CONSELHOS DE SAÚDE NO BRASIL}

Os conselhos de saúde existem desde janeiro de 1937, quando o Conselho Nacional de Saúde foi instituído pela Lei no 378 (BRASIL, 1937). Nasceram com o objetivo de auxiliar o então Ministério da Educação e Saúde Pública, que cuidava somente de algumas endemias (LUCENA; MIRANDA, 2011).

Em 1970, durante o governo de Emílio Garrastazu Médici, o Conselho Nacional de Saúde passou a ter funções normativas e foi legitimado pelo Estado, o que garantiu seu melhor funcionamento. Em 1976, por meio do Decreto no 79.056 (BRASIL, 1976), foi regulamentado, passando a funcionar de forma semelhante ao coletivo de Câmaras Técnicas (LUCENA; MIRANDA, 2011).

O que se instaurou de diferente em 1986 é que esse Conselho, que tinha um papel meramente técnico, passou a ser formado também por usuários, ser participativo, devendo ter papel decisivo nas políticas de saúde a serem instituídas (LUCENA; MIRANDA, 2011).

A realização da $8{ }^{a}$ Conferência de Saúde em 1986 (MINISTÉRIO DA SAÚDE, 1986) foi um marco para a participação da comunidade nas decisões atinentes à saúde, pois a ideia de que a saúde fosse planejada a partir das necessidades da população e com base nas conferências resultou na finalização de seu relatório.

Segundo a Lei $n^{\circ}$ 8.142/90 (BRASIL, 1990b), que dispõe sobre a participação da comunidade na gestão do SUS por meio das conferências e dos conselhos de saúde, a conferência de saúde deverá "reunir-se a cada quatro anos com a representação dos vários segmentos sociais, para avaliar a situação de saúde e propor as diretrizes para a formulação da política de saúde nos níveis correspondentes" e o conselho de saúde, "órgão colegiado composto por representantes do governo, prestadores de serviço, profissionais de saúde e usuários, atuará na formulação de estratégias e no controle da execução da política de saúde na instância correspondente”.

Os conselhos de saúde são considerados os principais órgãos de representação da sociedade civil perante os sistemas de saúde nas três esferas de governo (municipal, estadual e federal), tornando-se o principal elo entre sociedade e Estado na busca pela participação social democrática na elaboração e na execução de políticas públicas (ALMEIDA; TATAGIBA, 2012).

A Resolução n 33/92 (BRASIL, 1992), que trata dos conselhos de saúde, fala que em sua composição deverá haver paridade dos usuários em relação aos demais segmentos, ou seja, $50 \%$ dos representantes do conselho deverão ser usuários, enquanto os outros $50 \%$ deverão ser de representantes dos demais segmentos - neste caso, o Conselho Nacional de Saúde recomenda que eles sejam distribuídos da seguinte maneira: trabalhadores de saúde (25\%) e prestadores de serviços públicos e privados (25\%).

De acordo com a mesma Resolução, os conselhos não devem possuir menos de 10 nem mais de 20 membros e os representantes dos usuários devem ser indicados pelas entidades ou pelos movimentos aos quais pertencem. Segundo Almeida e Tatagiba (2012), essa composição torna o processo decisório mais permeável aos diferentes interesses sugeridos na elaboração e na execução das políticas públicas, favorecendo decisões mais justas e verdadeiras. 
Algumas condições, segundo o Ministério da Saúde (BRASIL, 1992), contribuem para um melhor desempenho dos conselhos de saúde: autonomia, organicidade, permeabilidade, visibilidade e articulação. A autonomia é quando um conselho tem condições administrativas, financeiras e técnicas adequadas para seu desenvolvimento. A organicidade é caracterizada pelo grau de organização dos conselhos. A permeabilidade é a condição estabelecida em um conselho que já consegue atender às necessidades de saúde emergentes nas comunidades locais. A visibilidade é uma condição que se caracteriza pela transparência da atuação dos conselhos, e a articulação significa a capacidade de os conselhos realizarem a intercomunicação com os conselhos gestores em geral. Todas essas condições partem do princípio de que um conselho deve ser representativo e ter legitimidade para funcionar adequadamente.

O mais recente documento que trata dos conselhos de saúde é a Resolução 333/03 (BRASIL, 2003), que substitui a Resolução 33/92 (BRASIL, 1992) e estabelece as diretrizes para criação, reformulação, estruturação e funcionamento dos conselhos de saúde.

Atualmente, o que se percebe em grande parte da revisão da literatura é que a participação social conquistada com imensa luta se tornou invisível aos olhos da sociedade e na política brasileira, com vários desfechos negativos dessa atuação (FLEURY; LOBATO, 2009).

Nota-se isso quando se olha para trás e se vê que uma das principais lutas políticas associadas à criação e ao funcionamento dos conselhos estava relacionada à garantia do seu papel deliberativo no interior do sistema das políticas públicas. O fato é explicado quando se observa que o adjetivo "deliberativo" abriga as expectativas de que tais instâncias invertam prioridades e, dessa forma, que os recursos públicos sejam distribuídos de forma mais justa, fazendo assim a diferença como instância decisória. Mas, infelizmente, por diversas questões, os conselhos deixam de exercer não só seu papel deliberativo, mas outros também tão importantes para o alcance da democracia (ALMEIDA; TATAGIBA, 2012).

O desconhecimento do verdadeiro papel dos conselhos e dos conselheiros, a distância que é interposta entre os membros do conselho (por exemplo, gestores com linguagem inacessível aos outros), a falta de legitimidade, principalmente dos usuários, são alguns dos problemas vistos em sua composição e que acabam impossibilitando esse órgão de exercer uma democracia deliberativa e efetiva (FLEURY; LOBATO, 2009).

Portanto, acredita-se haver a necessidade de reinventar a democracia nesses espaços por meio da qualificação do processo decisório de todos os membros, emancipando-os, de maneira a torná-los agentes ativos para interferir positivamente nas políticas de saúde.

\section{O PROCESSO DECISÓRIO NOS CONSELHOS DE SAÚDE}

Entendendo que o processo decisório é parte importante para que os conselheiros tomem decisões sobre as políticas de saúde, faz-se necessário que ele seja apreendido em suas características e componentes.

Antes, porém, são necessárias algumas considerações sobre a questão da participação nesses espaços. Sabe-se que a maior parte dos membros dos conselhos municipais de saúde é representada pelos usuários — voz da sociedade perante o sistema de saúde —, mas o que se vê é a falta de participação efetiva dessa representação nessas arenas de decisões (KLEBA; WENDHAUSEN, 2009). 
Essa situação tem fortes laços com a história política, na qual o regime centralizado e autoritário distancia seu trabalhador de qualquer tomada de decisão, tornando-o menos autônomo, ativo e participativo (MORITA e col., 2006). Essa correlação entre a história política e a participação social, de fato representada pelos conselhos municipais de saúde, é concretizada quando se observa, nesses fóruns de decisões, o distanciamento existente entre os representantes dos usuários e os demais membros, a pauta dos assuntos a serem discutidos e o controle da agenda que geralmente é centralizado pelo gestor da saúde (MOREIRA; ESCOREL, 2009a).

Parte-se do princípio de que, para se alcançar a efetivação de uma participação social democrática, é preciso começar a compreender e mediar o processo decisório nos espaços de discussão — os conselhos municipais de saúde —, que é a base para o alcance dos princípios do SUS (integralidade, universalidade e equidade).

O processo decisório é formado por uma variedade de decisões tomadas por representantes em diferentes arenas políticas. Não tem início, meio e fim definido; é um complexo caminho no qual são discutidas e implementadas ações de políticas públicas (LINDBLOM, 1981).

O alcance de um processo decisório qualificado não depende somente de “quem” participa, se há debate, "como" é discutido e o que se delibera, mas depende também de "o quê" ocupa maior espaço na agenda das reuniões (PERISSINOTTO e col., 2003). Por isso, um dos principais elementos que compõe o processo decisório é a formulação da agenda.

A agenda é um documento que deve ser formulado por todos os membros do conselho de saúde, definindo temas a serem discutidos, conforme a realidade e a necessidade da população de abrangência (LINDBLOM, 1981).

Com esse documento, os membros do conselho de saúde conseguem discutir os temas prioritários de interesse geral e local, formulando estratégias, acompanhando e avaliando a execução dessas ações junto de outros órgãos da saúde. Mas, na maioria das vezes, a agenda é formulada somente pelos gestores, criando um distanciamento com os outros representantes (LINDBLOM, 1981).

As discussões dos assuntos presentes na agenda nem sempre são positivas. Em estudos realizados, vários foram os problemas citados pelos conselheiros de saúde, como: os assuntos reivindicados pelos representantes dos usuários muitas vezes não aparecem na agenda, os assuntos da agenda geralmente são predeterminados e definidos pelas pessoas com maior autoridade e autonomia, e esses assuntos são facilmente levados por essas pessoas às lideranças, por ter fácil acesso (WENDHAUSEN; CARDOSO, 2007). Segundo Almeida e Tatagiba (2012), os conselhos têm desempenhado funções mais técnicas e burocráticas, mantendo uma agenda no "varejo" e atendendo às necessidades provenientes do Executivo, enquanto decisões importantes para as políticas públicas continuam sem soluções.

Além da agenda, o processo decisório envolve outros componentes que devem ser compreendidos, como: as características de cada participante, o papel que cada um exerce, a qual autoridade e a que tipo de poder está submetido, e como se dá o relacionamento entre os membros. Embora a análise desse processo seja bastante complexa, é necessário fazê-la para que se conheçam os problemas ali existentes (LINDBLOM, 1981).

Um problema central que se deve descrever se refere ao conhecimento dos representantes sobre seu papel no conselho. Os gestores querem dominar a instância com conhecimentos técnicos, 
linguagem inacessível aos outros e com a legitimidade que lhes foi conferida por terem sido indicados por representantes eleitos pela maioria da população. Os profissionais interferem, utilizando-se da prerrogativa de que não há atenção à saúde sem sua participação. E os usuários, por representarem a maioria dos conselheiros (50\%), sentem-se obrigados a controlar as ações do gestor, em vez de participar do processo deliberativo (MOREIRA; ECOREL, 2009b).

Essas relações hierárquicas de poder podem interferir de maneira negativa na participação dos usuários, impossibilitando que nos conselhos seja exercida uma democracia deliberativa e efetiva (MOREIRA; ESCOREL, 2009b).

Outro apontamento sobre essa hierarquia nos conselhos é apresentado por Wendhausen (2002), quando coloca que os representantes usuários geralmente são pessoas com baixa escolaridade, enquanto os demais membros possuem, em sua maioria, algum curso universitário na área da saúde. Entretanto, há que se problematizar se o baixo nível de escolaridade propicia condições de constrangimentos e discriminação aos usuários com relação aos outros conselheiros na discussão dos assuntos e na tomada de decisões.

Outra questão, apontada por Moreira e Escorel (2009b), refere-se à influência do grau de conhecimento e informação que o conselheiro tem sobre o sistema de saúde e as relações estabelecidas com o poder executivo na participação dos usuários. Segundo os autores, os que têm menos recursos não conseguem intervir na mudança de padrão e a linguagem técnica e Os argumentos burocráticos usados pela gestão dificultam e desqualificam a participação dos usuários.

Com essa falta de emancipação, a capacidade deliberativa dos conselhos e o processo de produção das políticas públicas acabam se tornando um problema. Tatagiba (2005) aponta alguns motivos relacionados à dinâmica de funcionamento dos conselhos, que podem estar causando esses problemas, sendo eles: centralidade do Estado na elaboração da pauta, falta de capacitação dos conselheiros, problemas com a representatividade, dificuldade em lidar com a pluralidade de interesses, manutenção de padrões clientelistas na relação entre Estado e sociedade, recusa do Estado em partilhar o poder.

Em estudo realizado com o Conselho Municipal de Saúde de Botucatu/SP, Morita e col. (2006) observaram a disposição padronizada da localização dos conselheiros na sala onde ocorriam as reuniões: os mais articulados sempre se agrupavam e tomavam assentos nas primeiras fileiras, enquanto os mais tímidos e menos participativos preferiam lugares mais ao fundo ou fora do eixo de discussões. Nesse mesmo estudo, algumas reclamações feitas por conselheiros chamaram a atenção, como o recebimento de "pacotes prontos" vindos das estruturas superiores, a exemplo de projetos de campanhas ou modelos de atuação, que têm se tornado um problema, pois não foram efetuadas adaptações condizentes com a realidade social e epidemiológica da sociedade.

A fragilidade da participação popular pode ser considerada positiva para os gestores de saúde no nível municipal, haja vista a possibilidade de obtenção e o uso de recursos sem consulta prévia, aprovação de contas e planos de aplicação dos recursos sem debates subsequentes, pois grande parte dos conselheiros não tem conhecimento prévio (GRISOTTI e col., 2010).

Considerando que os conselheiros representam um "grupo", tendo um grande compromisso com este, acredita-se de fato que esses representantes devem estar cientes de seu verdadeiro papel e da importância de sua representatividade, valorizando efetivamente esses canais. 
Contudo, o que realmente deve predominar nessas arenas de decisões é a democracia participativa, pela qual a comunidade participa, trazendo assuntos de seu interesse com a finalidade de problematizar e implementar ações que busquem a construção de algo novo.

\section{CONSIDERAÇÕES FINAIS}

Com este estudo, conseguiu-se visualizar a importância de reinventar a democracia nos conselhos de saúde por meio da qualificação dos elementos do processo decisório, fortalecendo o controle social e interferindo efetivamente na política de saúde. No entanto, vários fatores se mostram impeditivos para o bom funcionamento dos conselhos de saúde, como: falta da representação dos usuários como membros ativos da sociedade no processo de construção e transformação; falta de informação aos membros sobre o funcionamento e as funções dos conselheiros; dinâmica das reuniões sendo determinada na maioria das vezes pela representação da gestão, que leva assuntos somente de seu interesse; ausência de interlocução entre os membros e os demais conselhos de saúde; preparação da agenda sem discussão com todos os membros, o que dificulta a resolução dos reais problemas da sociedade; falta de conhecimento, principalmente da gestão, sobre a importância da participação da sociedade no controle social do SUS.

Considerou-se que a qualificação do processo decisório nessas arenas de discussão deve acontecer precocemente, porque somente após os membros saberem de suas funções e terem conhecimento acerca da participação social, da saúde e suas políticas, eles poderão transformar a realidade de sua sociedade, identificando as necessidades e propondo novas diretrizes políticoadministrativas para a saúde pública de seu município. Caso contrário, será visto o cenário proposto por Almeida e Tatagiba (2012), que colocam que os conselhos poderão se tornar mais um dos nichos secretos do Estado se não houver mudanças na dinâmica das reuniões e na forma de como acontece a participação dos membros.

\section{REFERÊNCIAS}

ALMEIDA, Carla; TATAGIBA, Luciana. Os conselhos gestores sob o crivo da política: balanços e perspectivas. Revista Serviço Social \& Sociedade. São Paulo, n. 109, p. 68-92, jan-mar 2012.

BORBA, Julian. O significado político dos conselhos gestores de políticas públicas. In: Encontro de Pesquisa em Saúde: o SUS e a atenção à saúde da família e I Mostra de Pesquisa e Extensão do CCS, Itajaí. Anais do II Encontro. Itajaí: Univali, 2004. p. 33-42.

BRASIL. Decreto no 79.056, de 30 de dezembro de 1976. Dispõe sobre a organização do Ministério da Saúde e dá outras providências. Brasília, DF, Diário Oficial da União, 31 dez. 1976.

BRASIL. Lei no 378, de 13 de janeiro de 1937. Dá nova organização ao Ministério da Educação e Saúde Pública. Brasília, DF, Diário Oficial da União, 15 jan. 1937.

BRASIL. Lei $\mathbf{n}^{\mathbf{0}} \mathbf{8 . 0 8 0}$, de 19 de setembro de 1990. Dispõe sobre as condições para a promoção, proteção e recuperação da saúde, a organização e o funcionamento dos serviços correspondentes e dá outras providências. Brasília, DF, Diário Oficial da União, 20 set. 1990a.

BRASIL. Lei $\mathbf{n}^{\circ} \mathbf{8 . 1 4 2}$, de 28 de dezembro de 1990. Dispõe sobre a participação da comunidade na gestão do Sistema Único de Saúde (SUS) e sobre as transferências intergovernamentais de recursos financeiros na área da saúde e dá outras providências. Brasília, DF, Diário Oficial da União, 31 dez. 1990b. 
BRASIL. Ministério da Saúde. Conselho Nacional de Saúde. A prática do controle social: conselhos de saúde e financiamento do SUS. Brasília: Ministério da Saúde, 2002.

BRASIL. Ministério da Saúde. Conselho Nacional de Saúde. Resolução nº 33, de 23 de dezembro de 1992. Recomendações para a constituição e estruturação de conselhos estaduais e municipais de saúde. Brasília: Ministério da Saúde, 1992.

BRASIL. Ministério da Saúde. Conselho Nacional de Saúde. Resolução no 333, de 04 de novembro de 2003. Aprova as diretrizes para criação, reformulação, estruturação e funcionamento dos conselhos de saúde. Brasília, DF, Diário Oficial da União, 4 dez. 2003.

FLEURY, Sonia; LOBATO, Lenaura de Vasconcelos Costa (Org.). Participação, democracia e saúde. Rio de Janeiro: Cebes, 2009.

GRISOTTI, Márcia; PATRICIO, Zuleica Maria; SILVA, Andréia. A participação e usuários, trabalhadores e conselheiros de saúde: um estudo qualitativo. Revista Ciência \& Saúde Coletiva, Rio de Janeiro, v. 15, n. 3, p. 831-840, 2010.

KLEBA, Maria Elisabeth da Silva. Descentralização do sistema de saúde no Brasil. Chapecó: Argos, 2005.

KLEBA, Maria Elisabeth da Silva; WENDAUSEN, Águeda. Empoderamento: processo de fortalecimento dos sujeitos nos espaços de participação social e democratização política. Revista Saúde e Sociedade, São Paulo, vol.18, n.4, p. 733-743, 2009.

LABRA, Maria Eliana. Capital social y consejos de salud en Brasil. Caderno Saúde Pública, Rio de Janeiro, v. 18 (suplemento), p. 47-55, 2002.

LINDBLOM, Charles Edward. O processo de decisão política. Brasília: Universidade de Brasília, 1981.

LOBATO, de Vasconcelos Costa (Org.). Prefácio. In: FLEURY, Sonia; LOBATO, Lenaura de Vasconcelos Costa. Participação, democracia e saúde. Rio de Janeiro: Cebes, 2009. p. 7-12.

LUCENA, Karla; MIRANDA, Denise. Conselho Nacional de Saúde: instrumento de controle social. CNS em Revista, Brasília, v. 1, n. 1, p. 8-9, set. 2011.

MINISTÉRIO DA SAÚDE. $\mathbf{8}^{\mathbf{a}}$ Conferência Nacional de Saúde: relatório final. Brasília: Ministério da Saúde, 1986.

MOREIRA, Marcelo Rasga; ESCOREL, Sarah. Conselhos municipais de saúde do Brasil: um debate sobre a democratização da política de saúde nos vinte anos do SUS. Revista Ciência \& Saúde Coletiva, Rio de Janeiro, v. 14, n. 3, p. 795-805, 2009a.

MOREIRA, Marcelo Rasga; ESCOREL, Sarah. Desafios da participação social em saúde na nova agenda da reforma sanitária: democracia deliberativa e efetividade. In: FLEURY, Sonia; LOBATO, Lenaura de Vasconcelos Costa (Org.). Participação, democracia e saúde. Rio de Janeiro: Cebes, 2009b. p. 229-247.

MORITA, Ione; GUIMARÃES, Juliano Fernandes Campos; MUZIO, Paulino Di Muzio. A Participação de conselheiros municipais de saúde: solução que se transformou em problema? Revista Saúde e Sociedade, São Paulo, v. 15, n. 1, p. 49-57, jan-abr 2006.

PERISSINOTTO, Renato Monseff; FUKS, Mario; SOUZA, Nelson Rosário. Participação e processo decisório em alguns conselhos de Curitiba. Revista Paranaense de Desenvolvimento, Curitiba, n. 105, p. 75-100, jul-dez 2003. 
TATAGIBA, Luciana. Conselhos gestores de políticas públicas e democracia participativa: aprofundando o debate. Revista de Sociologia e Política, Curitiba, v. 25, p. 209-213, nov. 2005.

WENDHAUSEN, Águeda. O duplo sentido do controle social: (des)caminhos da participação em saúde. Itajaí: Univali, 2002.

WENDHAusen, Águeda; CARDOSO, Sandra de Mello. Processo decisório e conselhos gestores de saúde: aproximações teóricas. Revista Brasileira de Enfermagem, Brasília, v. 60, n. 5, p. 579-584, setout 2007. 